\title{
HUBUNGAN DUKUNGAN SOSIAL DAN PENYAKIT KRONIS DENGAN KUALITAS HIDUP LANSIA DI BALAI PELAYANAN DAN PENYANTUNAN LANSIA PROVINSI BENGKULU
}

\section{Relationship Between Social Support And Chronic Disease With The Quality Of Life Of Elderly In The Center Of Service And Sponsorship Elderly Bengkulu Province}

\author{
Nova Oktavia $^{1}$, Dwi Fransiska ${ }^{2}$ \\ Akademi Kesehatan Sapta Bakti Bengkulu \\ nova.oktavia80@gmail.com
}

\begin{abstract}
ABSTRAK
Jumlah Lansia pada tahun 2010 berjumlah 18,1 juta jiwa, pada tahun 2030 diperkirakan akan mencapai 36 juta. Dengan semakin meningkatnya populasi lanjut usia akan menyertai potensi permasalahan yang meningkat pula sehingga membutuhkan penanganan yang serius karena secara alamiah lanjut usia akan mengalami penurunan baik dari segi biologis, sosial, maupun psikilogis yang berdampak pada kemampuan lanjut usia untuk beradaptasi dan bertahan hidup. Penelitian ini bertujuan untuk mengetahui hubungan dukungan sosial dan penyakit kronis dengan kualitas hidup lansia. Jenis penelitian ini adalah observasional analitik, dengan rancangan Cross-Sectional. Populasi penelitian ini adalah seluruh lansia yang tinggal di BPPLU Tresna Werda Bengkulu yang berjumlah 57 orang, dengan jumlah sampel 36 yang memenuhi kriteria inklusi dan eksklusi. Penelitian ini menggunakan data primer dan sekunder, yang dikumpulkan dengan menggunakan kuesioner. Analisa data menggunakan analisis univariat (distribusi frekuensi) dan bivariat (uji chi-quare). Penelitian ini dilakukan pada bulan Juli 2016 di BPPLU Tresna Werda Bengkulu. Hasil analisis univariat didapatkan bahwa dari 36 lansia, sebagian besar yaitu 21 (58,3\%) lansia memiliki dukungan sosial kurang baik, sebagian besar yaitu $22(61,1 \%)$ lansia menderita penyakit kronis dan sebagian besar yaitu $20(55,6 \%)$ lansia memiliki kualitas hidup kurang baik. Hasil analisis bivariat didapatkan bahwa ada hubungan yang bermakna antara dukungan sosial dan penyakit kronis dengan kualitas hidup lansia dengan nilai $\mathrm{p}=0,000$ (nilai $\mathrm{p}<\alpha=0.05$ ). Diharapkan pada pihak BPPLU Tresna Werda Bengkulu untuk lebih memperhatikan kebutuhan dan memantau aktifitas lansia agar kebutuhan nutrisi, kebersihan diri dan kondisi kesehatan lansia terpenuhi serta keamanan fisik terjaga.
\end{abstract}

\section{Kata Kunci : Dukungan Sosial, Penyakit Kronis, Kualitas Hidup, Lansia}

\begin{abstract}
The number of elderly people in 2010 was 18.1 million, in 2030 it is estimated to reach 36 million. With the increasing elderly population, it will accompany the increasing potential problems that require serious handling because of naturally, the elderly will experience a decline both in terms of biological, social, and psychological aspects that affect the ability of the elderly to adapt and survive. This study aims to determine the relationship between social support and chronic diseases with the quality of life of the elderly. This type of research is observational analytic, with crosssectional design. The population of this study was all elderly people who lived in the BPPLU Tresna Werda Bengkulu, amounting to 57 people, with a sample of 36 who met the inclusion and exclusion criteria. This study uses primary and secondary data, which was collected using a questionnaire. Data
\end{abstract}


analysis using univariate analysis (frequency distribution) and bivariate (chi-quare test). This research was conducted in July 2016 at the BPPLU Tresna Werda Bengkulu. The results of univariate analysis showed that of 36 elderly people, most of whom were 21 (58.3\%) the elderly had poor social support, most of them are $22(61.1 \%)$ elderly suffer from chronic diseases and most of them are $20(55.6 \%)$ of the elderly who have poor quality of life. The results of the bivariate analysis showed that there was a significant relationship between social support and chronic disease with the quality of life of the elderly with $\mathrm{p}$ value $=0,000(<\alpha=0.05)$. It is expected that the BPPLU Tresna Werda Bengkulu will pay more attention to the needs and monitor the activities of the elderly so that the nutritional needs, personal hygiene and health conditions of the elderly are met and physical security is maintained.

Key word: Social Support, Chronic Diseases, The Quality of Life, Elderly 


\section{PENDAHULUAN}

Menurut Kementrian Kesehatan RI (2013), keberhasilan pembangunan adalah cita-cita suatu bangsa yang terlihat dari peningkatan tarif hidup dan Umur Harapan Hidup (UHH) atau Angka Harap Hidup (AHH). Namun peningkatan UHH ini dapat mengakibatkan terjadinya transisi epidemiologi dalam bidang kesehatan akibat meningkatnya jumlah angka kesakitan karena penyakit degeneratif. Perubahan struktur demografi ini diakibatkan oleh peningkatan populasi lanjut usia (Lansia) dengan menurunya angka kematian serta penurunan jumlah kelahiran. UHH di Indonesia pada tahun 2011 yaitu 69,65 tahun (dengan prensentasi populasi lansia adalah 7,58\%), angka ini akan meningkat pada tahun 2045-2050 yang diperkirakan UHH menjadi 77,6 tahun (dengan presentasi populasi lansia tahun 2045 adalah 28,68\%). WHO (World Health Organization) menyatakan lansia sebagai tahap akhir siklus kehidupan merupakan tahap perkembangan normal yang akan dialami oleh setiap individu yang mencapai usia lanjut dan merupakan kenyataan yang tak dapat dihindari.

Secara demografi, lansia di Indonesia termasuk lima besar terbanyak di dunia dengan jumlah lansia sesuai sensus penduduk 2010 berjumlah 18,1 juta jiwa (9,6\% dari total penduduk), pada tahun 2030 diperkirakan akan mencapai 36 juta (Kemenkes, 2013) Dengan semakin meningkatnya populasi lanjut usia akan menyertai potensi permasalahan yang meningkat pula sehingga membutuhkan penanganan yang serius karena secara alamiah lanjut usia akan mengalami penurunan baik dari segi biologis, sosial, maupun psikilogis yang berdampak pada kemampuan lanjut usia untuk beradaptasi dan bertahan hidup sehingga berubah menjadi individu yang dependen. Kenyataan sekarang ini lansia di Indonesia masih berkualitas rendah, banyak diantara mereka masih tergantung pada anak atau keluarga lain dan kurang produktif sehingga mempengaruhi kualitas hidup lanjut usia (Fauziah, 2011)

Kualitas hidup adalah sejauh mana seseorang dapat merasakan dan menikmati terjadinya segala peristiwa penting dalam kehidupannya sehingga kehidupannya menjadi sejahtera (Rapley, 2003 dan Brown 2004). Kualitas hidup dipengaruhi oleh beberapa faktor diantaranya kesehatan fisik, psikologi, dukungan sosial, Lingkungan, fungsi keluarga, penyakit kronis (konsumsi obat-obatan), ekonomi dan status gizi (Gabriel \& Bowling, 2004; Sutikno, 2011)

Pada usia lanjut terjadi kemunduran sel-sel karena proses penuaan yang dapat berakibat pada kelemahan organ, kemunduran fisik, timbulnya berbagai macam penyakit terutama penyakit degeneratif. Berbagai penyakit degeneratif seperti jantung koroner, stroke, patah tulang akibat osteoporosis, demensia dan penyakit lain yang berlangsung lama seperti hipertensi, arthritis, diabetes mellitus, gastritis (Kemenkes, 2013). Hutapea (2005) menyatakan bahwa sekitar 50-80\% Lansia yang berusia $\geq 65$ tahun akan menderita lebih dari satu penyakit kronis. Penyakit kronis merupakan suatu penyakit yang perjalanan penyakitnya berlansung lama sampai bertahun-tahun, bertambah berat, menetap dan sering kambuh. Masalah penyakit kronis sangat mempengaruhi Lansia sepanjang hidupnya.

Penyakit kronis akan menyebabkan masalah medis, social dan psikologis yang akan membatasi aktivitas dari Lansia 
sehingga akan menyebabkan penurunan kualitas hidup Lansia (Hutapea, 2005). Penyakit kronis yang dialami tersebut tentunya juga akan diikuti dengan konsumsi obat-obatan. Konsumsi obatobatan pada lansia diketahui mempengaruhi kualitas hidup. Penurunan fungsi fisik serta adanya gejala dan keluhan karena penyakit kronis sering menyebabkan lansia mengkonsumsi lebih dari 1 jenis obat. Penggunaan lebih dari 1 jenis obat tersebut berkaitan dengan penurunan kualitas hidup dimensi kesehatan fisik (Henderson, 2006). Teori ini didukung oleh hasil penelitian Sari (2013) menyatakan bahwa penyakit kronis dan konsumsi obat-obatan berhubungan dengan kualitas hidup lansia dan hasil penelitian Rohmah (2012), menyatakan terdapat pengaruh faktor fisik terhadap kualitas hidup lanjut usia.

Setelah seseorang memasuki masa lansia, maka dukungan sosial dari orang lain menjadi sangat berharga dan akan menambah ketentraman hidup nya (Kuntjoro, 2014) Dukungan sosial adalah adanya bantuan atau dukungan yang diterima individu dari orang lain dalam kehidupannya sehingga individu tersebut merasa bahwa orang lain memperhatikan, menghargai, dan mencintainya. Dukungan sosial dapt berasal dari internal maupun eksternal. Dukungan eksternal diperoleh dari sahabat, pekerja panti sosial, tetangga, keluarga besar, kelompok sosial, kelompok rekreasi, kelompok ibadah, praktisi kesehatan. Dukungan sosial internal diperoleh dari suami atau istri, dari saudara kandung, atau dukungan dari anak (Setiadi, 2010). Teori ini didukung oleh hasil penelitian Burhan (2013) menyatakan bahwa dukungan sosial dari care giver terutama dari keluarga yang diberikan oleh pasangan berhubungan positif terhadap kualitas hidup lansia. Hasil penelitian Syahrir (2015) dan Rahmiati (2014) menyatakan bahwa interaksi atau dukungan sosial khususnya dari teman sebaya / sesama lansia memiliki hubungan dengan kualitas hidup lansia.

Berasarkan hasil survey yang telah dilakukan bulan Mei 2016 didapatkan bahwa jumlah lansia di Balai Pelayanan dan Penyantunan Lanjut Usia (BPPLU) Tresna Werda Bengkulu 61 orang. Yang terdiri dari 42 laki-laki dan 19 perempuan. Lansia yang mengalami penyakit Degeneratif dan kronis terdiri dari rematik 41 orang, demensia 35 orang, hipertensi 31 orang, asam urat 28 orang, Diabetes militus 18 orang, gastritis 17 orang, katarak 16 orang,inkontinensia urine 5 orang. Dari 10 lansia, 2 lansia mempunyai kualitas hidup baik, 6 lansia punya kualitas hidup cukup, dan 2 lansia memiliki kualitas hidup kurang baik. Sedangkan dukungan sosial yang diukur dengan menggunakan APGAR Skor didapat 3 lansia memiliki status sosial tidak baik dan 7 lansia memiliki status sosial baik. Penelitian ini bertujuan untuk menganalisis hubungan dukungan sosial dan penyakit kronis dengan kualitas hidup lansia di Balai Pelayanan dan Penyantunan Lanjut Usia (BPPLU) Tresna Werda Bengkulu Tahun 2016

\section{BAHAN DAN METODE}

Jenis penelitian ini adalah observasional analitik dengan menggunakan rancangan penelitian cross sectional yaitu variabel bebas (dukungan sosial dan penyakit kronis) dan variabel terikat (kualitas hidup lansia) diukur dalam waktu yang bersamaan. Populasi penelitian ini adalah seluruh lanjut usia yang tinggal di Balai Pelayanan dan Penyantunan Lanjut Usia (BPPLU) Tresna Werda 
Bengkulu sebanyak 57 orang. Sampel penelitian ini keseluruhan dari populasi yaitu 57 orang, namun yang memenuhi kriteria inklusi sebanyak 36 orang. Penelitian ini menggunakan data sekunder/registes yang meliputi data jumlah lansia dan data penyakit kronis dari buku catatan klinik di BPPLU. Sedangkan data primer dalam penelitian ini meliputi data dukungan sosial dan data kualitas hidup yang didapat dari melakukan wawancara. Instrumen yang digunakan bivariat untuk melihat hubungan antara variabel independen (dukungan sosial dan penyakit kronis) dengan variabel dependen untuk mengukur dukungan sosial yaitu APGAR keluarga (Mubarak dkk, 2012). Sedangkan mengukur kualitas hidup menggunakan Kuesioner WHOQOLBREF dimodifikasi dengan WHOQOLOLD yang diadopsi dari Riasmini (2012).

Penelitian ini telah dilakukan pada bulan juli 2016, di Balai Pelayanan dan Penyantunan Lanjut Usia (BPPLU) Tresna Werda Bengkulu. Setelah data terkumpul, dianalisis secara univariat menggunakan tabel distribusi frekuensi dan analisis (kualitas hidup lansia) menggunakan uji statistik Chi-Square dengan tingkat kemaknaan $5 \%$.

\section{HASIL PENELITIAN}

Tabel 1. Distribusi Frekuensi Dukungan Sosial, Penyakit Kronis, Kualitas Hidup Lansia di BPPLU Tresna Werda Bengkulu

\begin{tabular}{lccc}
\hline & Variabel & $\mathrm{N}$ & $\%$ \\
\hline Dukungan Sosial & Baik & 15 & 41,7 \\
& Kurang baik & 21 & 58,3 \\
\hline \multirow{2}{*}{ Penyakit Kronis } & Jumlah & 36 & 100 \\
& Ya & 22 & 61,1 \\
& Tidak & 14 & 38,9 \\
\hline Kualitas Hidup & Jumlah & 36 & 100 \\
& Baik & 16 & 44,4 \\
& Kurang & 20 & 55,6 \\
\hline
\end{tabular}

Berdasarkan tabel 1 dari 36 lansia, sebagian besar yaitu $21(58,3 \%)$ lansia memiliki dukungan sosial kurang baik, sebagian besar yaitu $22(61,1 \%)$ lansia menderita penyakit kronis dan sebagian besar yaitu $20(55,6 \%)$ lansia memiliki kualitas hidup kurang baik.

Tabel 2. Hubungan Dukungan Sosial Dengan Kualitas Hidup Lansia di BPPLU Tresna Werda Bengkulu Tahun 2016

\begin{tabular}{|c|c|c|c|c|c|c|c|c|}
\hline \multirow{3}{*}{$\begin{array}{c}\text { Dukungan } \\
\text { Sosial }\end{array}$} & \multicolumn{4}{|c|}{ Kualitas Hidup } & \multirow{2}{*}{\multicolumn{2}{|c|}{ Jumlah }} & \multirow{3}{*}{$\begin{array}{c}\text { PR } \\
(\mathrm{CI} 95 \%) \\
6.067(2.089-\end{array}$} & \multirow{3}{*}{$p$ value } \\
\hline & \multicolumn{2}{|c|}{ Baik } & \multicolumn{2}{|c|}{ Kurang } & & & & \\
\hline & $\mathrm{N}$ & $\%$ & $\mathrm{n}$ & $\%$ & $\mathrm{n}$ & $\%$ & & \\
\hline Baik & 13 & 86,7 & 2 & 13,3 & 15 & 100 & 17.621) & 0.000 \\
\hline Kurang baik & 3 & 14,3 & 18 & 85,7 & 21 & 100 & & \\
\hline Jumlah & 16 & 44,4 & 20 & 55,6 & 36 & 100 & & \\
\hline
\end{tabular}


Bardasarkan tabel 2 dapat dilihat bahwa dari 15 lansia yg memiliki dukungan sosial baik, sebagian besar yaitu $13(86,7 \%)$ lansia memiliki kualitas hidup cukup dan baik dan dari 21 lansia yang memiliki dukungan sosial kurang baik yaitu sebagian besar $18(85,7 \%)$ memiliki kualitas hidup kurang baik. Berdasarkan hasil uji statistik menggunakan chi-square di dapatkan ada hubungan yang bermakna antara dukungan sosial dengan kualitas hidup pada lansia, dengan nilai $\mathrm{p}=0,000$ (nilai $\mathrm{p}<\alpha=0.05$ ). Lansia yang memiliki dukungan sosial yang kurang baik beresiko 6,067 kali memiliki kualitas hidup yang kurang baik di bandingkan dengan lansia yang memiliki dukungan sosial baik.

Tabel 3. Hubungan Penyakit Kronis Dengan Kualitas Hidup Lansia di BPPLU Tresna Werda Bengkulu Tahun 2016

\begin{tabular}{|c|c|c|c|c|c|c|c|c|}
\hline \multirow{3}{*}{$\begin{array}{c}\text { Penyakit } \\
\text { Kronis }\end{array}$} & \multicolumn{4}{|c|}{ Kualitas Hidup } & \multirow{2}{*}{\multicolumn{2}{|c|}{ Jumlah }} & \multirow{2}{*}{$\begin{array}{c}\text { PR } \\
\text { (CI 95\%) }\end{array}$} & \multirow{2}{*}{$p$ value } \\
\hline & \multicolumn{2}{|c|}{ Baik } & \multicolumn{2}{|c|}{ Kurang } & & & & \\
\hline & $\mathrm{N}$ & $\%$ & $\mathrm{n}$ & $\%$ & $\mathrm{n}$ & $\%$ & 4.714 & \\
\hline $\mathrm{Ya}$ & 4 & 18,2 & 18 & 81,8 & 22 & 100 & (1.894-1.734) & 0.000 \\
\hline Tidak & 12 & 85,7 & 2 & 14,3 & 14 & 100 & & \\
\hline Jumlah & 16 & 44,4 & 20 & 55,6 & 36 & 100 & & \\
\hline
\end{tabular}

Bardasarkan tabel 3 dapat dilihat bahwa dari 22 lansia yang memiliki penyakit kronis, sebagian besar yaitu 18 $(81,8 \%)$ lansia memiliki kualitas hidup kurang baik dan dari 14 lansia yang tidak memiliki penyakit kronis yaitu sebagian besar $12(85,7 \%)$ memiliki kualitas hidup Baik. Berdasarkan hasil uji statistik menggunakan chi-square di dapatkan bahwa ada hubungan yang bermakna antara penyakit kronis dengan kualitas hidup pada lansia, dengan nilai $\mathrm{p}=0,000$ (nilai $\mathrm{p}<\alpha=0.05$ ). Lansia yang memiliki penyakit kronis beresiko 4,714 kali memiliki kualitas hidup yang kurang baik di bandingkan dengan lansia yang tidak memiliki penyakit kronis.

\section{PEMBAHASAN}

1. Hubungan dukungan sosial dengan kualitas hidup lansia di BPPLU Tresna Werda Bengkulu tahun 2016

Berdasarkan tabel 2 dari 15 lansia yang memiliki dukungan sosial baik sebagian besar yaitu $13(86,7 \%)$ memiliki kualitas hidup Baik. Hasil penelitian ini sejalan dengan teori Kuntjoro (2014) yang menyatakan bahwa dukungan sosial merupakan bantuan atau dukungan yang diterima individu dari orang lain dalam kehidupannya sehingga individu tersebut merasa bahwa orang lain memperhatikan, menghargai, dan mencintainya. Dukungan sosial dapt berasal dari internal maupun eksternal. Dukungan eksternal diperoleh dari sahabat, pekerja panti sosial, tetangga, keluarga besar, kelompok sosial, kelompok rekreasi, kelompok ibadah, praktisi kesehatan. Dukungan sosial internal diperoleh dari suami atau istri, dari saudara kandung, atau dukungan dari anak (Setiadi, 2010).

Teori ini didukung oleh hasil penelitian Burhan (2013) menyatakan bahwa dukungan sosial dari care giver terutama dari keluarga yang diberikan oleh pasangan berhubungan positif terhadap kualitas hidup lansia. Hasil analisis uji chisquare membuktikan ada hubungan yang signifikan antara dukungan sosial dengan 
kualitas hidup lnsia, hasil penelitian ini sejalan dengan Hasil penelitian Syahrir (2015) dan Rahmiati (2014) menyatakan bahwa interaksi atau dukungan sosial khususnya dari teman sebaya/sesama lansia memiliki hubungan dengan kualitas hidup lansia.

Dari 15 lansia yang memiliki dukungan sosial baik sebagian kecil yaitu $2(13,3 \%)$ memiliki kualitas hidup kurang baik. hal ini dikarenakan adanya beberapa lansia yang mengalami gangguan psikologi seperti depresi. Depresi pada usia lanjut akan mempengaruhi dampak yang cukup serius pada kehidupan sosial dan fisik dimana hal tersebut akan menyebabkan penurunan kulitas hidup serta menyebabkan lanjut usia bergantung pada orang (Mangoenprasodjo \& Hidayati, 2005) Dan dari 36 lansia, 6 lansia mendapat kunjungan dari keluarga ataupun kerabatnya. Hal ini sejalan dengan teori, Wicke (2014) yang menyatakan bahwa dukungan sosial yang berasal dari kerabat, teman, dan orang-orang terdekat lainnya serta yang memiliki ikatan emosional dapat membantu dalam perbaikan kualitas hidup lansia khususnya dalam hal kesehatan. Selain itu, terdapat 5 pasang suami istri dimana mereka saling mendapat dukungan, kasih sayang dan perhatian dari pasangannya, hal ini sejalan dengan hasil penelitian Burhan dkk, (2013) yang menyatakan bahwa lansia yang diasuh oleh pasangan memiliki kualitas hidup lebih baik, sebab bagi lansia adanya orang kedua seperti pasangan hidup menjadi sangat penting bagi kualitas kehidupan mereka, pasangan dianggap orang yang paling mengerti kehidupan mmereka.

Dari 21 lansia yang memiliki dukungan sosial kurang baik,sebagian kecil yaitu $3(14,3)$ memiliki kualitas Baik.
Selain dukungan sosial faktor yang mempengaruhi kualitas hidup diantaranya faktor kesehatan fisik, setatus gizi. Dan pada beberapa lansia ini memiliki kesehatan fisik dan setatus gizinya baik, maka kualitas hidupnya juga baik. Kualitas hidup lansia dipengaruhi oleh beberapa faktor yang menyebabkan seorang lansia untuk tetap bisa berguna dimasa tuanya, yakni kemampuan menyesuaikan diri dan menerima segala perubahanyang di alami, adanya penghargaan dan perlakuan yang wajar dari lingkungan lansia tersebut (Kuntjoro, 2014). Tiori ini didukung oleh hasil penelitian ini terutama pada kuesioner 14 yang menanyakan tentang lingkungaan sekitar menghargai lansia didapat kan bahwa keseluruhan lansia mengatakan puas dan sangat puas terhadap lingkungan sekitarnya atau lansia merasa dihargai oleh temannya dipanti.

Dari 21 lansia yang memiliki dukungan sosial kurang baik, sebagian besar yaitu $18(85,7 \%)$ memiliki kualitas hidup kurang baik. Hal ini sesuai dengan teori Kuntjoro (2014) yang menyatakan bahwa setelah seseorang memasuki masa lansia, maka dukungan sosial dari keluarga, teman sebaya, orang lain menjadi sangat berharga dan akan menambah ketentraman hidupnya, sehingga jika dukungan sosial tersebut kurang baik, maka akan berpengaruh terhadap kualitas hidup lansia tersebut. Berkurang waktu untu bertemu dengan keluarga menyebabkan para lansia akan merasa tidak mendapatkan kebahagiaan dari keluarganya. Terdapat beberapa masalah yang biasa dialami oleh lansia diantaranya adalah kesepian, keterasingan dari lingkungan, ketidakberdayaan, ketergantungan, kurang percaya diri, keterlantaran terutama bagi lansia yang 
miskin serta kurangnya dukungan dari anggota keluarga (Yulianti, 2013)

2. Hubungan penyakit kronis dengan kualitas hidup lansia di BPPLU Tresna Werda Bengkulu Tahun 2016

Berdasarkan tabel 3 dari 14 lansia yang tidak mengalami penyakit kronis sebagian besar yaitu $12(85,7 \%)$ memiliki kualitas hidup Baik. Hal ini dikarenakan setiap hari rabu petugas kesehatan yang ada di Klinik BPPLU Tresna Werda melakukan pemeriksaan kesehatan dan pengobatan gratis kepada lansia. Dan untuk kebutuhan makan, lansia mendapatkan makan 2x/hari yang disediakan oleh petugas panti serta makanan lain yang diberikan oleh pihak lain (donatur). Kebutuhan kualitas hidup berhubungan dengan kemampuan dan kapasitas lansia untuk memenuhi kebutuhan tertentu. Kualitas hidup berada pada tingkat tertinggi ketika semua terpenuhi, dan terendah ketika kebutuhan sedikit tidak terpenuhi. Kebutuhan yang dimaksud diantaranya identitas, status, harga diri, kasih sayang, cinta, keamanan, kesenangan, kreatifitas, makanan, tidur, menghindari rasa sakit, kegiatan, dan lainnya (Fauziah, 2011). Teori ini didukung hasil penelitian ini terutama pada kuesioner no 12 yang menyatakan tentang kebebasan lansia dalam mengambil keputusan, karena lansia hanya tinggal bersama teman-teman nya yang jauh dari keluargannya.

Dari 14 lansia yang tidak mengalami penyakit kronis, sebagian kecil yaitu $2(14,3 \%)$ memiliki kualitas hidup kurang baik. karena kurangnya dukungan sosial,dari lingkungan sekitar, Kualitas hidup dipengaruhi oleh beberapa faktor diantaranya kesehatan fisik, psikologi, dukungan sosial, lingkungan, fungsi keluarga, penyakit kronis (konsumsi obatobatan), ekonomi dan status gizi (Gabriel \& Bowling, 2004; Sutikno, 2011) Lingkungan tempat tinggal menjadi faktor penting yang berpengaruh terhadap kualitas hidup lansia. Lingkungan tempat tinggal yang berbeda mengakibatkan perubahan peran lansia dalam menyesuikan diri, beradaptasi dengan lingkungan baru dan berinteraksi dengan lingkungan sosialnya (Yuliati, 2013).

Dari 22 lansia yang mengalami penyakit kronis, sebagian kecil 4 (18,2\%) memiliki kualitas hidup Baik. Kehilanggan dan beratnya penyakit dapat menyebabkan kualitas hidup lansia (Wiggins et al, 2004). Proses menua tetap menimbulkan permasalahan baik secara fisik, biologis, mental maupun sosial ekonimi, dari mereka mengungkapkan dan mengeluh tentang kehidupannya dimasa tua yang sangat susah. Mereka merasa terbatas aktifitasnya, sering sakit, lingkungan kurang bersahabat, dan tidak percaya diri dengan penampilan fisiknya sekarang, ini menjadi rendah nya kualitas hidup lanjut usia (Darmajo, 2004). Semakin tua umur berarti kualitas hidupnya semakin buruk. Hal ini disebabkan karena dengan bertambahnya umur terdapat penurunan fisik, perubahan mental, perubahan psikososial antara lain pensiun, akan kehilangan finansial, status, temen/kenalan, pekerjaan, kegiatan, merasakan atau sadar akan kematian, perubahan dalam carahidup seperti kesepian, hidup sendiri, perubahan ekonomi, penyakit kronis, ketidak mampuan, kehilangan kekuatan dan ketegapan fisik (Nugroho, 2002)

Dari 22 lansia yang mengalami penyakit kronis, sebagian besar $18(81,8 \%)$ memiliki kualitas hidup kurang baik. Penyakit kronis merupakan suatu penyakit 
yang perjalanan penyakitnya berlangsung lama sampai bertahun-tahun, bertambah berat, menetap dan sering kambuh seperti hipertensi, arthritis, deabetes melitus, grastritis dan lain-lain. Dalam penelitian ini ditemukan bahwa masalh penyakit kronis terbanyak adalah hipertensi, hipertensi merupakan penyakit kronis yang dapat menimbulkan gejala-gejala seperti sakit kepala, depresi, cemas, sulit berkonsentrasi, mudah marah, dan berdampak pada aspek sosial dimana lansia tidak mau bersosialisasi karena merasakan kondisinya yang tidak nyaman. Hal ini menyebabkan penurunan kualitas hidup personal sosial, memberikan pengaruh buruk terhadap vitalitas, fungsi sosial, kesehatan mental dan fungsi fikologisnya. Insiden hipertensi meningkat seiring dengan bertambahnya usia. Hal ini sejalan dengan penelitian Soni (2013) dengan penelitian dimana hipertensi menempati $87 \%$ kasus pada orang yang berusia diatas 60 tahun, menyebutkan $65 \%$ orang diatas usia 65 tahun menderita hipertensi. Masalah penyakit kronis sangat mempengaruhi lansia sepanjang hidupnya. Penyaki kronis akan menyebabkan masalah medis, social dan psikologis yang akan membatasi aktivitas dari lansia sehingga akan menyebabkan penurunan kualitas hidup lansia (Hutapea, 2005).

Hasil analisis uji chi-square membuktikan ada hubungan yang signifikan antara penyakit kronis dengan kualitas hidup lnsia, hasil penelitian ini sejalan dengan hasil penelitian Sari (2013), yang menyatakan bahwa ada hubungan yang bermakna antara penyakit kronis dan konsumsi obat-obatan dengan kualitas hidup dimensi kesehatan fisik pada lansia di Kecamatan Cilacap Utara. Dengan adanya penyakit kronis pada lansia dapat menurunkan kualitas hidup kususnya dimensi kesehatan fisik (Adelman, 2001).Penyakit kronis yang dialami tersebut tentu juga akan diikuti dengan konsumsi obat-obatan pada lansia diketahui mempengaruhi kualitas hidup. Penurunan fungsi fisik serta adanya gejala dan keluhan karena penyakit kronis sering menyebabkan lansia mengonsumsi lebih dari 1 jenis obat. Penggunaan lebih dari satu jenis obat tersebut berkaitan dengan penurunan kualitas hidup dimensi keehatan fisik (Hutapea, 2005)

\section{KESIMPULAN}

Berdasarkan hasil penelitian yang diperoleh, maka dapat disimpulkan ada hubungan yang bermakna antara dukungan sosial dengan kualitas hidup dan ada hubungan yang bermakna antara penyakit kronis dengan kualitas hidup lansia di BPPLU Tresna Werda Bengkulu.

\section{SARAN}

Diharapkan pada pihak BPPLU Tresna Werda Bengkulu untuk lebih memperhatikan kebutuhan dan memantau aktifitas lansia agar kebutuhan nutrisi, kebersihan diri dan kondisi kesehatan lansia terpenuhi, keamanan fisik terjaga.

\section{DAFTAR PUSTAKA}

Adelman, D. (2001). Penyakit-penyakit kronis yang mempengaruhi kehidupan lansia. (diakses 20 oktober 2013), diunduh http://eprints.usu.ac.id/17322

Burhan, N. I. K. (2013). Hubungan Care Giver Terhadap Status Gizi Dan Kualitas Hidup Lansia Pada Etnis Bugis. JST Kesehatan, 3, 264-273.

Brown, J, et all. (2004). Models of Quality of Life: A Taxonomy, Overview and Systematic Review of The Literatur. 
European Forum on Population Ageing Research.

Fauziah, A. (2011). Peran Kecemasan dan Defresi Terhadap Kualitas Hidup Lansia di PPSLU Mappakasunggu Pare-pare. Skripsi: Universitas Hasanudin Makassar

Gabriel, Z \& Bowling, A. (2004). Quality of Life From the Perspectives of Older People. Ageing \& Society 24: 675-691.

Henderson AJ, Buchwald D, Manson SM. Relationship of Medication Use to Health-Related Quality of Life Among a Group of Older American. J Appl Gerontol. 2006;20(10): 1-15.

Hutapea, R. (2005) sehat dan ceria diusia senja. Jkarta: Rineka Cipta

Kemenkes R.I. (2013). Infodatin, Situasi dan Analisis Lanjut Usia. Jakarta: Kemenkes RI

Kuntjoro, Z. S (2014). Pendekatan dukungan sosial keluarga. Diakses pada tanggal 24 mei 2016 dari www.e-psikologi.com

Mubarak., Iqbal, W., Cahayatin, Santoso, N., Adi, B. (2009) Ilmu Keperawata Komunitas 2. Jakarta: Salemba Medika

Rahmianti. (2014). Hubungan Pola Makan, Status Gizi, Dan Interaksi Sosial Dengan Kualitas Hidup Lansia Suku Bugis Di Kelurahan Sapanang Kabupaten Pangkep. Skripsi. Makassar: Universitas Hasanuddin.

Rapley, M. (2003). Quality of Life Research: a critical introduction : Sage Publications. Page: 53, 54, 92

Riasmini, M.N. (2012 ) Evektivitas Model Kelompok Keluarga Mandiri Untuk Meningkatkan Kualitas Hidup Lanjut Usia dimasyarakat Wilayah DKI
Jakarta.distraksi: $\quad$ Universitas Indonesia

Rohmah, A.I.N., Purwaningsih., Bariya, K. Kualitas Hidup Lanjut Usia. Jurnal Keperawatan, ISSN 2086-3071. Juli 2012: 120-132

Sari, N, K (2013) Setatus Gizi, Penyakit Kronis, dan Konsumsi Obat Terhadap Kualitas Hidup Demensi Kesehatan Fisik Lansia (skripsi). Semarang

Setiadi. 2010. Konsep dan Proses Keperawatan Keluarga. Yogyakarta: Graha llmu

Soni, R.K et al. 2010. Health- Related Quality of Life in Hypertension, Chronic Kidney Disease, and Coexixtent Chronic Condition. 2013.

Sutikno, E. 2011. Hubungan antara Fungsi Keluarga dengan Kualitas Hidup Lansia. Med J Indones; 2011: 9-73

Syahrir, P. (2015). Hubungan Dukungan Sosial Dengan Kualitas Hidup Lansia Dipanti Sosial Tresna Werdha Gau Mabaji Kabupaten Gowa. Skripsi. Makassar: Universitas Hasanuddin. 